\title{
Occupational exposures among nurses and risk of spontaneous abortion
}

\section{Citation}

Lawson, Christina C., Carissa M. Rocheleau, Elizabeth A. Whelan, Eileen N. Lividoti Hibert, Barbara Grajewski, Donna Spiegelman, and Janet W. Rich-Edwards. 2012. “Occupational Exposures among Nurses and Risk of Spontaneous Abortion." American Journal of Obstetrics and Gynecology 206 (4): 327.e1-327.e8. https://doi.org/10.1016/j.ajog.2011.12.030.

\section{Permanent link}

http://nrs.harvard.edu/urn-3:HUL.InstRepos:41384678

\section{Terms of Use}

This article was downloaded from Harvard University's DASH repository, and is made available under the terms and conditions applicable to Other Posted Material, as set forth at http:// nrs.harvard.edu/urn-3:HUL.InstRepos:dash.current.terms-of-use\#LAA

\section{Share Your Story}

The Harvard community has made this article openly available. Please share how this access benefits you. Submit a story.

Accessibility 


\title{
Occupational exposures among nurses and risk of spontaneous abortion
}

\author{
Christina C LAWSON, Ph.D. ${ }^{1}$, Carissa M. ROCHELEAU, Ph.D. ${ }^{1}$, Elizabeth A WHELAN, Ph.D. \\ ${ }^{1}$, Eileen N. LIVIDOTI HIBERT, M.A. ${ }^{2}$, Barbara GRAJEWSKI, Ph.D. ${ }^{1}$, Donna SPIEGELMAN, \\ Sc.D. ${ }^{3,4}$, and Janet W. RICH-EDWARDS, Sc.D. ${ }^{3,5}$ \\ ${ }^{1}$ National Institute for Occupational Safety and Health, Centers for Disease Control and \\ Prevention; Cincinnati, $\mathrm{OH}$ \\ ${ }^{2}$ Channing Laboratory, Department of Medicine, Brigham and Women's Hospital, and Harvard \\ Medical School; Boston, MA \\ ${ }^{3}$ Department of Epidemiology, Harvard School of Public Health; Boston, MA \\ ${ }^{4}$ Department of Biostatistics, Harvard School of Public Health; Boston, MA \\ ${ }^{5}$ Connors Center for Women's Health and Gender Biology, Brigham and Women's Hospital; \\ Boston, MA
}

\begin{abstract}
Objective-We investigated self-reported occupational exposure to antineoplastic drugs, anesthetic gases, antiviral drugs, sterilizing agents (disinfectants), and X-rays and the risk of spontaneous abortion in U.S. nurses.
\end{abstract}

Study Design-Pregnancy outcome and occupational exposures were collected retrospectively from 8,461 participants of the Nurses' Health Study II. Of these, 7,482 were eligible for analysis using logistic regression.

Results-Participants reported 6,707 live births, and 775 (10\%) spontaneous abortions $(<20$ weeks). After adjusting for age, parity, shift work, and hours worked, antineoplastic drug exposure was associated with a 2-fold increased risk of spontaneous abortion, particularly with early spontaneous abortion before the $12^{\text {th }}$ week, and 3.5-fold increased risk among nulliparous women.

\footnotetext{
Address correspondence and reprint requests to: Christina C. Lawson, Ph.D., CDC/NIOSH, 4676 Columbia Parkway, R-15, Cincinnati, Ohio 45226, 513-841-4171 (phone), 513-841-4486 (fax), clawson@cdc.gov.

Disclosure: None of the authors has a conflict of interest.

Presentation information:
}

1. $3^{\text {rd }}$ North American Congress of Epidemiology; Montreal, Quebec, Canada; June 23, 2011

2. NORA symposium 2011; Cincinnati, OH; July 13, 2011

Disclaimer: The findings and conclusions in this report are those of the author(s) and do not necessarily represent the views of the National Institute for Occupational Safety and Health.

Publisher's Disclaimer: This is a PDF file of an unedited manuscript that has been accepted for publication. As a service to our customers we are providing this early version of the manuscript. The manuscript will undergo copyediting, typesetting, and review of the resulting proof before it is published in its final citable form. Please note that during the production process errors may be discovered which could affect the content, and all legal disclaimers that apply to the journal pertain. 
Exposure to sterilizing agents was associated with a 2-fold increased risk of late spontaneous abortion (12-20 weeks), but not with early spontaneous abortion.

Conclusion-This study suggests that certain occupational exposures common to nurses are related to risks of spontaneous abortion.

\section{Keywords}

antineoplastic agents; health personnel; occupational exposure; pregnancy

\section{INTRODUCTION}

Over two million women are employed as nurses, ${ }^{1}$ representing $4 \%$ of all employed women in the US. ${ }^{2}$ Nurses are potentially exposed to several suspected reproductive hazards, including anesthetic gases, antineoplastic (chemotherapy) drugs, antiviral drugs, sterilizing agents (disinfectants), and X-rays (ionizing radiation). ${ }^{3-9}$ Though the nursing profession is a critical component of the health care system, the effect of commonly encountered occupational exposures on reproductive health remains unclear within this predominantly female occupation.

Many previous studies of nursing exposures and spontaneous abortion lack adequate numbers of exposed cases to allow adjustment for confounders. Even though awareness of hazardous drug exposure has increased, protocols to reduce exposure of health care personnel to these chemicals have been insufficient to eliminate the exposure. ${ }^{10,11}$ To clarify previous study results, we investigated the association between reported occupational exposures and risk of spontaneous abortion among participants of the Nurses' Health Study II.

\section{MATERIALS AND METHODS}

The Nurses' Health Study II was established in 1989 as a prospective cohort study of 116,430 U.S. nurses, aged 25 to 42, in 14 states. Participants completed mailed questionnaires regarding their medical and reproductive history at baseline and were sent follow-up questionnaires every two years. In the 2001 questionnaire, participants were asked if they had experienced at least one pregnancy since 1993 and had worked as a nurse during the most recent of those pregnancies. If so, participants were asked whether they would be willing to complete a mailed supplemental questionnaire regarding occupational activities during their most recent pregnancy.

Among the 101,681 respondents to the 2001 biennial questionnaire, 11,177 (11\%) had a pregnancy since 1993 during which they worked as a nurse. Willingness to complete the supplemental survey was indicated by 9,547 (85\%) participants; 8,461 (89\%) of these women completed and returned the supplemental survey they were mailed, resulting in an overall participation rate of $76 \%$ for the supplement. Since multiple pregnancies per woman are not independent events, we asked only about the most recent pregnancy.

Pregnancies ending in an induced abortion $(n=147)$, ectopic pregnancy $(n=57)$, molar pregnancy $(n=13)$, or multiple pregnancy $(n=235)$, as well as 7 pregnancies with a missing 
pregnancy outcome, were excluded. Stillbirths, defined as a pregnancy loss after 20 weeks gestation, were also excluded ( $n=42)$. Pregnancies were excluded if the participant reported that the pregnancy was not confirmed by a clinical or over-the-counter pregnancy test $(n=130)$, as well as pregnancies without data on the year the pregnancy ended $(n=31)$ or the length of the pregnancy $(n=22)$. Women who reported working less than 1 hour per week as a nurse during the first trimester of pregnancy $(n=65)$; or who did not provide information on shift work $(n=24)$, anesthetic gases $(n=19)$, sterilizing agents $(n=91)$, antineoplastic drugs $(n=14)$, antiviral drugs $(n=33)$, or X-rays $(n=49)$; were also excluded. In total, $979(11.6 \%)$ women were excluded, leaving data on 7,482 women in the analysis.

For each trimester of pregnancy, the following questions were asked: "On average how many hours per day did you work with the following agents:" and the following categories, with examples, were given "a. Anesthetic gases (e.g. nitrous oxide, halothane, enflurane, isoflurane)," "b. Anti-cancer drugs (e.g. Cytoxan, Fluroplex, Adrucil, Etoposide, 5-FU)," "c. Anti-viral drugs (e.g. Gancyclovir or the interferons)," "d. Sterilizing agents (e.g. ethylene oxide, formaldehyde, glutaraldehyde)," and "e. X-ray radiation." Data on work schedule, night work, average hours worked per week, frequency of lifting 25 pounds or more at work, hours per day of standing or walking at work, smoking, alcohol consumption, and caffeine consumption were also collected for each trimester of pregnancy. From the main biennial questionnaires, data were also available on age, race/ethnicity, body mass index (BMI), medication use, parity, and prior spontaneous abortion.

Participants reported the outcome of the index pregnancy as a single live birth, stillbirth, twins, triplets+, induced abortion, tubal/ectopic pregnancy, miscarriage, or molar pregnancy. Categorical information on pregnancy duration was reported on the supplemental survey as weeks since last menstrual period (less than 8, 8-11, 12-19, 20-23, 24-27, 28-31, 32-36, $37-41$ (full-term), and 42 or more weeks). Pregnancies ending involuntarily before 20 weeks gestation were classified as spontaneous abortions.

Completion of the self-administered questionnaire was considered implied informed consent. The study and informed consent procedure were approved by the Institutional Review Board of the Brigham and Women's Hospital.

Descriptive statistics (frequency, range, and age-adjusted means) were calculated for selected maternal characteristics. The relationship between spontaneous abortion and firsttrimester exposure to anesthetic gases, antineoplastic agents, sterilizing agents, antiviral drugs, and X-rays was examined in univariable and multivariable analyses. We modeled age as a continuous variable. Because the risk of spontaneous abortion rose exponentially with age, we also included a quadratic age term (age-squared) in the models. Exposure categories were dichotomized as $1+$ hour per day versus $<1$ hour per day for all reported exposures.

For univariable and multivariable analyses, we used logistic regression to compute the odds ratio (OR) using SAS software. Covariates that changed the estimate by $10 \%$ or more were retained in the final multivariate model.

We first considered the associations of these individual exposures with risk of spontaneous abortion, adjusted for age. Our full multivariable model included all 5 work exposures of 
interest, age, parity, and work schedule. The addition of lifestyle and other factors, such as cigarette smoking, caffeine consumption, alcohol consumption, BMI, race/ethnicity, lifting at work, and standing at work did not change the estimated effects by more than $10 \%$. Because previous occurrence of spontaneous abortion could have been due to the same environmental or occupational exposures studied in the index spontaneous abortion, and to avoid possible bias, we did not adjust for previous spontaneous abortion in these analyses. ${ }^{12}$ Our primary analysis looked at all spontaneous abortions as the outcome. In our secondary analysis, we stratified by the timing of the spontaneous abortion, since early and late spontaneous abortion may be controlled by different mechanisms, and the percentage of spontaneous abortions due to chromosomal abnormalities decreases as gestational age increases. ${ }^{13}$ For this analysis, early spontaneous abortion is modeled as $<12$ weeks gestation, and late spontaneous abortion as 12-20 weeks. For the analysis of late spontaneous abortions, early spontaneous abortions were excluded $(n=575)$. To assess statistically significant differences between early and late models, we calculated p-values for common effects with a chi-square test statistic using the maximum likelihood estimates from the logistic regression. We also assessed interactions between parity and each exposure by modeling a cross-product interaction term in a model containing the main effects of parity and the exposure, as well as other covariates.

\section{RESULTS}

Among 7,482 eligible participants, the pregnancies of 775 (10\%) ended in spontaneous abortion. Seventy-four percent of those ended before the $12^{\text {th }}$ week of pregnancy $(n=575)$. The year of the pregnancies ranged from 1993-2002 (the mean year was 1996), with 82\% occurring between 1993 and 1998. The spontaneous abortion rate varied by specialty area; the lowest rates were for medical/surgical and critical care (8.4\% and $8.8 \%$, respectively), and the highest rates for home health/community and oncology (13.1\% for each). However, $32 \%$ of nurses specified "other" as their specialty area (11.0\% spontaneous abortion rate).

Table 1 shows age-adjusted prevalence of selected characteristics of eligible participants by pregnancy outcome. Women whose pregnancies ended in spontaneous abortion were older and less likely to be parous than those with live births. Prior spontaneous abortion, higher consumption of caffeinated beverages and alcohol, and cigarette smoking were also more common among pregnancies ending in spontaneous abortion. Occupational exposures were reported more often in spontaneously aborted pregnancies, particularly exposure to antineoplastic drugs - which was reported nearly twice as often compared to live births (Table 2). As previously reported, ${ }^{14}$ women whose pregnancies failed were more likely to have worked the night shift and to have worked long hours during the first trimester than women with live births.

Table 3 provides estimated odds ratios and $95 \%$ confidence intervals $(95 \% \mathrm{CI})$ for the associations between occupational exposures and spontaneous abortion in three models. First, we evaluated the associations between each individual exposure and spontaneous abortion (adjusted for age), showing increased risks for spontaneous abortion with reported exposure to antineoplastic drugs, sterilizing agents, and X-rays. When simultaneously adjusting for age and all five work exposures, these three exposures were still associated 
with spontaneous abortion, though X-ray exposure was of borderline statistical significance. Further adjustment for parity, shift work, and hours worked per week had modest impact, and showed that nurses reporting occupational exposure to antineoplastic drugs had a $94 \%$ increased risk of spontaneous abortion, while exposure to sterilizing agents had a 39\% increased risk. To evaluate if exclusion of pregnancies not confirmed by a pregnancy test resulted in any bias, we analyzed the final model without this exclusion, and the results were nearly identical.

Because nulliparous women might have underlying sub-fertility that may make them more susceptible to effects of reproductive hazards, we conducted a secondary analysis by parity. We evaluated the multiplicative interaction between each exposure and parity (yes/no), adjusted for age, shift work, hours worked, and each of the occupational exposures. There were $240(19.2 \%)$ spontaneous abortions among the 1,249 nulliparous women and 535 spontaneous abortions among the 6,233 parous women (8.9\%). Only antineoplastic drugs appeared to interact with parity (interaction $\mathrm{p}=0.04$ ), with stronger associations among nulliparas (3.50, 95\% CI 1.79-6.87) than among parous women (1.44, 0.88-2.36)

Because early spontaneous abortions may have different etiologies than later pregnancy loss, ${ }^{13}$ we conducted a sub-analysis stratified by gestational age of the pregnancy for early loss (less than 12 weeks gestation, $n=575)$ versus late loss $(12-20$ weeks gestation, $n=200$ ). The results-- adjusted for all work exposures, age, parity, shift work and hours worked per week-- are shown in Table 4. The stratified analysis shows that reported exposures to antineoplastic drugs [OR=2.13 (95\% CI= 1.39-3.27)] and, to a lesser extent, $\mathrm{X}$-rays $[\mathrm{OR}=1.31(95 \% \mathrm{CI}=1.01-1.71)]$ were associated with an increased risk for early pregnancy loss. Reported exposure to sterilizing agents was associated with later pregnancy loss $[\mathrm{OR}=2.10(95 \% \mathrm{CI}=1.29-3.41)]$ but not with early spontaneous abortion; the difference between the two models was statistically significant ( $\mathrm{p}$-value $=0.04)$.

\section{COMMENT}

We found that exposure to some of the agents commonly used by health care workers, including antineoplastic drugs, sterilizing agents, and X-rays, were associated with an increased risk of spontaneous abortion. Antineoplastic drugs are handled by nurses, pharmacists, physicians, operating room personnel, workers in veterinary practices, and manufacturers; exposures can occur during manufacture, preparation, administration, and contact with patient waste products..$^{15}$ Recognized as teratogenic and mutagenic, antineoplastic agents act on rapidly proliferating cells and are therefore of particular concern for a developing fetus. ${ }^{16-18}$ Previous studies have had mixed results, and many suffer from limited sample sizes. The three largest studies ${ }^{19-21}$ showed increased risks for spontaneous abortion with self-reported first trimester exposure through handling or mixing, mostly among oncology nurses or pharmacists (ORs ranging from 1.5-2.3) in samples that included from 18 to 223 exposed cases. Other studies did not find statistically significant associations ${ }^{22-27}$ with ORs ranging from $0.7-2.8$, and limited sample sizes (3 to 34 exposed cases). A meta-analysis pooled the results of five studies ${ }^{19-21,24,25}$ and found an overall adjusted increased risk of $46 \%(95 \% \mathrm{CI}=11 \%-92 \%) .{ }^{28}$ Only one of these studies ${ }^{25}$ occurred after safe handling measures were first recommended in $1985 .{ }^{29,}{ }^{30}$ However, since 
1985, several exposure studies still report drug contamination on work surfaces in pharmacies and patient rooms. ${ }^{31} \mathrm{NIOSH}$ recently updated the recommendations for safe handling of antineoplastic drugs. ${ }^{32}$

Our findings regarding exposure to sterilizing agents is consistent with our previously reported association of sterilizing agents with risk of preterm birth $(\mathrm{RR}=1.9,95 \% \mathrm{CI}=1.1-$ 3.4). ${ }^{33}$ Glutaraldehyde, formaldehyde, ethylene oxide, orthophthalaldehyde, peracetic acid, and hydrogen peroxide are used to disinfect medical equipment and surgical instruments. Ethylene oxide and formaldehyde are recognized as carcinogenic and mutagenic, but there have been few studies in humans to evaluate their reproductive toxicity, $3,34,35$ and most had limited sample sizes. Information regarding safe exposure levels for pregnant women is lacking. Future studies should build on these findings to clarify which specific sterilizing agents may pose risks to pregnant nurses, the specific context in which they are being used, and the efficacy of safe handling practices.

Though it is well-known that an acute dose of ionizing radiation is a reproductive hazard, the reproductive risks associated with occupational exposure to X-rays during pregnancy are not well defined. ${ }^{36}$ The current occupational exposure limit for ionizing radiation to the fetus of a pregnant worker is $5 \mathrm{mSv}(0.5 \mathrm{rem})$ cumulative during the course of the pregnancy, with a monthly equivalent dose limit of $0.5 \mathrm{mSv} .{ }^{37}$ Factors associated with the level of radiation include the source, distance from the source, use of a shielded control booth or leaded apron, and gestational age at the time of exposure. Health care workers, dental assistants, and veterinarians can be exposed via X-rays, CT scans, fluoroscopies, radioactive isotopes, and radioactive implants; these are listed in order of increasing relative biological effectiveness. A recent study found a 3 -fold higher spontaneous abortion rate among women occupationally exposed to radioisotopes compared to X-rays, ${ }^{38}$ suggesting a dose-response relationship. In addition, staff who use mobile $\mathrm{X}$-ray machines may find it difficult to follow guidelines to reduce exposure. ${ }^{7}$ A radiation safety officer can advise workers on atypical or nonstandard procedures where radiation exposure is unavoidable.

Anesthetic gases have long been of concern to nurses, dental workers, and veterinarians, though our study did not show an association with spontaneous abortion. ${ }^{6,39}$ A metaanalysis of studies that were conducted in the absence of scavenging systems reported increased risks for spontaneous abortion. ${ }^{40}$ Studies of dental and veterinary offices have found increased risks of spontaneous abortion in practices where anesthetic gases were not scavenged. ${ }^{41,42}$ More recent studies show inconsistent results, possibly due to sample size limitations ${ }^{42-44}$ or due to the heterogeneity of exposure. While appropriate engineering controls are commonplace in many hospital operating rooms, smaller medical facilities (such as dental, veterinary, or pediatric offices) may be less vigilant in controlling exposures. In addition, reduced ability of pediatric patients and veterinary animals to voluntarily cooperate during gas administration procedures could hamper the effectiveness of scavenging. Therefore, though our study supports the idea that the use of engineering controls has reduced the risk of spontaneous abortion, it does not rule out possible effects on pregnancy in smaller facilities. 
We could find no previous studies of occupational exposure to antivirals and spontaneous abortion. Because certain antivirals are considered to be teratogenic to animals, and are contraindicated during pregnancy according to the FDA, pregnant health care workers should be advised of potential risks when administering aerosolized antivirals. ${ }^{45}$

Though recall error is a potential limitation of our study, we attempted to minimize it by keeping the recall period relatively short $\left(<=8\right.$ years, mean of 5 years) ${ }^{46}$ In addition, Nurses' Health Study participants have been shown to self- report health data accurately for several medical conditions. ${ }^{47-49}$ Moreover, self-report of the duration of drug handling by pharmacists has been shown to be valid. ${ }^{50}$

However, there is still potential for recall bias, since the pregnancy outcomes were reported on the same instrument that collected occupational exposures. Though we cannot directly measure recall bias, we do not believe it is likely to explain our findings. First, we observed substantially different odds ratios for early versus late spontaneous abortions for antineoplastic agents and sterilizing agents. This observation is consistent with biological mechanisms, and it is not expected that recall bias would be differential based on whether the spontaneous abortion was early or late. In addition, we would expect recall bias to be highest for agents with the most awareness of potential hazard, ${ }^{51}$ such as X-rays; ${ }^{52}$ however, we noted only a small excess risk associated with exposure to X-rays.

An important limitation of our study is that we were not able to collect information on measures to control exposures, such as use of gloves, respirators, lead aprons, ventilation, or scavenging systems; nor did we collect information on types of agents being used, forms of administration, or sources of radiation. Future studies could improve on the current study with a more detailed exposure assessment instrument; such data are currently being collected in the Nurses' Health Study III.

The large sample size, narrow recall period, and ability to control for multiple exposures are improvements over previous studies. Though the homogeneity of the nurses in our study with respect to socio-economic status and education may decrease generalizability, it also likely reduced confounding. Unlike previous studies, we were also able to distinguish between early and late spontaneous abortions, which likely follow different mechanisms and etiologies, with early spontaneous abortions having a higher likelihood of being due to chromosomal abnormalities. ${ }^{13}$ Therefore, it is possible that earlier spontaneous abortions could be due to exposures which are mutagenic, whereas later spontaneous abortion may be the result of teratogenic exposures or exposures that affect the mother's ability to carry the infant to term. Further research is indicated to explore the differences we see in our data.

In conclusion, we found increased risks for spontaneous abortion with reported exposures to antineoplastic drugs, sterilizing agents, and X-rays. Although antineoplastic drugs and Xrays are known reproductive hazards, U.S. nurses are still reporting exposures to these during pregnancy. We encourage nurses who are pregnant, or who wish to become pregnant, to work with their employers and their health care providers to reduce exposures during pregnancy and lactation. 


\section{Acknowledgments}

Sources of financial support: This work was partially funded by contract \#200-2001-08007 from the Centers for Disease Control/National Institute for Occupational Safety and Health.

\section{References}

1. United States Department of Health and Human Services Administration DoN. The National Sample of Registered Nurses, 2000. 2002

2. Statistics USBoL. The Employment Situation: December 2004. 2005

3. Olfert SM. Reproductive outcomes among dental personnel: a review of selected exposures. J Can Dent Assoc. 2006; 72:821-5. [PubMed: 17109802]

4. Ahlborg G Jr, Hemminki K. Reproductive effects of chemical exposures in health professions. J Occup Environ Med. 1995; 37:957-61. [PubMed: 8520960]

5. Babich H. Reproductive and carcinogenic health risks to hospital personnel from chemical exposure--a literature review. J Environ Health. 1985; 48:52-6. [PubMed: 10274220]

6. Figa-Talamanca I. Reproductive problems among women health care workers: epidemiologic evidence and preventive strategies. Epidemiol Rev. 2000; 22:249-60. [PubMed: 11218376]

7. Shortridge-McCauley LA. Reproductive hazards: an overview of exposures to health care workers. AAOHN J. 1995; 43:614-21. [PubMed: 8694964]

8. Vainio H. Inhalation anesthetics, anticancer drugs and sterilants as chemical hazards in hospitals. Scand J Work Environ Health. 1982; 8:94-107. [PubMed: 7134932]

9. Vecchio D, Sasco AJ, Cann CI. Occupational risk in health care and research. Am J Ind Med. 2003; 43:369-97. [PubMed: 12645094]

10. Connor TH, DeBord DG, Pretty JR, et al. Evaluation of antineoplastic drug exposure of health care workers at three university-based US cancer centers. J Occup Environ Med. 2010; 52:1019-27. [PubMed: 20881620]

11. Gambrell J, Moore S. Assessing workplace compliance with handling of antineoplastic agents. Clin J Oncol Nurs. 2006; 10:473-7. [PubMed: 16927900]

12. Wilcox, AJ. Fertility and Pregnancy; an Epidemiologic Perspective. New York, NY: Oxford University Press;

13. Burgoyne PS, Holland K, Stephens R. Incidence of numerical chromosome anomalies in human pregnancy estimation from induced and spontaneous abortion data. Hum Reprod. 1991; 6:555-65. [PubMed: 1918307]

14. Whelan EA, Lawson CC, Grajewski B, Hibert EN, Spiegelman D, Rich-Edwards JW. Work schedule during pregnancy and spontaneous abortion. Epidemiology. 2007; 18:350-5. [PubMed: 17435444]

15. NIOSH. NIOSH Alert: Preventing Occupational Exposures to Antineoplastic and other Hazardous Drugs in Health Care Settings DHHS (NIOSH). 2004 Publication No 2004-165.

16. Azim HA Jr, Peccatori FA, Pavlidis N. Treatment of the pregnant mother with cancer: a systematic review on the use of cytotoxic, endocrine, targeted agents and immunotherapy during pregnancy. Part I: Solid tumors. Cancer Treat Rev. 2010; 36:101-9. [PubMed: 20015593]

17. Arnon J, Meirow D, Lewis-Roness H, Ornoy A. Genetic and teratogenic effects of cancer treatments on gametes and embryos. Hum Reprod Update. 2001; 7:394-403. [PubMed: 11476352]

18. FDA. Food and Drug Administration Advisory Committee on Protocols for Safety Evaluations. Panel on reproduction report on reproduction studies in the safety evaluation of food additives and pesticide residues. Toxicol Appl Pharmacol. 1970; 16:264-96. [PubMed: 5467148]

19. Stucker I, Caillard JF, Collin R, Gout M, Poyen D, Hemon D. Risk of spontaneous abortion among nurses handling antineoplastic drugs. Scand J Work Environ Health. 1990; 16:102-7. [PubMed: 2353192]

20. Valanis B, Vollmer WM, Steele P. Occupational exposure to antineoplastic agents: self-reported miscarriages and stillbirths among nurses and pharmacists. J Occup Environ Med. 1999; 41:632-8. [PubMed: 10457505] 
21. Selevan SG, Lindbohm ML, Hornung RW, Hemminki K. A study of occupational exposure to antineoplastic drugs and fetal loss in nurses. N Engl J Med. 1985; 313:1173-8. [PubMed: 4058490]

22. Fransman W, Roeleveld N, Peelen S, de Kort W, Kromhout H, Heederik D. Nurses with dermal exposure to antineoplastic drugs: reproductive outcomes. Epidemiology. 2007; 18:112-9. [PubMed: 17099323]

23. Hemminki K, Kyyronen P, Lindbohm ML. Spontaneous abortions and malformations in the offspring of nurses exposed to anaesthetic gases, cytostatic drugs, and other potential hazards in hospitals, based on registered information of outcome. J Epidemiol Community Health. 1985; 39:141-7. [PubMed: 3925060]

24. Skov T, Maarup B, Olsen J, Rorth M, Winthereik H, Lynge E. Leukaemia and reproductive outcome among nurses handling antineoplastic drugs. Br J Ind Med. 1992; 49:855-61. [PubMed: 1472444]

25. Peelen, SRN.; Heederik, D.; Krombout, H.; de Kort, W. Toxic effects on reproduction in hospital personnel. Dutch Ministry of Social Affairs and Employment; 1999.

26. Taskinen H, Lindbohm ML, Hemminki K. Spontaneous abortions among women working in the pharmaceutical industry. Br J Ind Med. 1986; 43:199-205. [PubMed: 3947584]

27. McDonald AD, Armstrong B, Cherry NM, et al. Spontaneous abortion and occupation. J Occup Med. 1986; 28:1232-8. [PubMed: 3806263]

28. Dranitsaris G, Johnston M, Poirier S, et al. Are health care providers who work with cancer drugs at an increased risk for toxic events? A systematic review and meta-analysis of the literature. $\mathrm{J}$ Oncol Pharm Pract. 2005; 11:69-78. [PubMed: 16465719]

29. Council on Scientific Affairs. Guidelines for handling parenteral antineoplastics. JAMA. 1985; 253:1590-92. [PubMed: 3974039]

30. Randall ME, Constable WC. Guidelines for handling parenteral antineoplastics. JAMA. 1985; 254:1033-34. [PubMed: 4021036]

31. Connor TH, McDiarmid MA. Preventing occupational exposures to antineoplastic drugs in health care settings. CA Cancer J Clin. 2006; 56:354-65. [PubMed: 17135692]

32. NIOSH. NIOSH Hazardous Drug Exposure in Health Care web page. 2010; 2010

33. Lawson CC, Whelan EA, Hibert EN, Grajewski B, Spiegelman D, Rich-Edwards JW. Occupational factors and risk of preterm birth in nurses. Am J Obstet Gynecol. 2009; 200:51 e1-8. [PubMed: 18976732]

34. Collins JJ, Ness R, Tyl RW, Krivanek N, Esmen NA, Hall TA. A review of adverse pregnancy outcomes and formaldehyde exposure in human and animal studies. Regul Toxicol Pharmacol. 2001; 34:17-34. [PubMed: 11502153]

35. Rowland AS, Baird DD, Shore DL, Darden B, Wilcox AJ. Ethylene oxide exposure may increase the risk of spontaneous abortion, preterm birth, and postterm birth. Epidemiology. 1996; 7:363-8. [PubMed: 8793361]

36. De Santis M, Di Gianantonio E, Straface G, et al. Ionizing radiations in pregnancy and teratogenesis: a review of literature. Reprod Toxicol. 2005; 20:323-9. [PubMed: 15925481]

37. NCRP. NCoRPaM. Limitation of exposure to ionizing raditation. NCRP report. 1993; (116):3739.

38. Fucic A, Merlo DF, Ceppi M, Lucas JN. Spontaneous abortions in female populations occupationally exposed to ionizing radiation. Int Arch Occup Environ Health. 2008; 81:873-9. [PubMed: 18058121]

39. US Department of Labor OSaHA. Anesthetic Gases: Guidelines for Workplace Exposures. 2000

40. Boivin JF. Risk of spontaneous abortion in women occupationally exposed to anaesthetic gases: a meta-analysis. Occup Environ Med. 1997; 54:541-8. [PubMed: 9326157]

41. Rowland AS, Baird DD, Shore DL, Weinberg CR, Savitz DA, Wilcox AJ. Nitrous oxide and spontaneous abortion in female dental assistants. Am J Epidemiol. 1995; 141:531-8. [PubMed: 7900720]

42. Shirangi A, Fritschi L, Holman CDJ. Maternal occupational exposures and risk of spontaneous abortion in veterinary practice. Occup Environ Med. 2008; 65:719-25. [PubMed: 18388114] 
43. Gauger VT, Voepel-Lewis T, Rubin P, Kostrzewa A, Tait AR. A survey of obstetric complications and pregnancy outcomes in paediatric and nonpaediatric anaesthesiologists. Paediatr Anaesth. 2003; 13:490-5. [PubMed: 12846704]

44. Shuhaiber S, Einarson A, Radde IC, Sarkar M, Koren G. A prospective-controlled study of pregnant veterinary staff exposed to inhaled anesthetics and X-rays. Int J Occup Med Environ Health. 2002; 15:363-73. [PubMed: 12608624]

45. Assessing exposures of health-care personnel to aerosols of ribavirin--California. MMWR Morb Mortal Wkly Rep. 1988; 37:560-3. [PubMed: 3137440]

46. Coughlin SS. Recall bias in epidemiologic studies. J Clin Epidemiol. 1990; 43:87-91. [PubMed: 2319285]

47. Rich-Edwards JW, Goldman MB, Willett WC, et al. Adolescent body mass index and infertility caused by ovulatory disorder. Am J Obstet Gynecol. 1994; 171:171-7. [PubMed: 8030695]

48. Colditz GA, Martin P, Stampfer MJ, et al. Validation of questionnaire information on risk factors and disease outcomes in a prospective cohort study of women. Am J Epidemiol. 1986; 123:894900. [PubMed: 3962971]

49. Colditz GA, Stampfer MJ, Willett WC, et al. Reproducibility and validity of self-reported menopausal status in a prospective cohort study. Am J Epidemiol. 1987; 126:319-25. [PubMed: 3605058]

50. McDiarmid MA, Kolodner K, Humphrey F, Putman D, Jacobson-Kram D. Baseline and phosphoramide mustard-induced sister-chromatid exchanges in pharmacists handling anti-cancer drugs. Mutat Res. 1992; 279:199-204. [PubMed: 1377335]

51. Savitz, DA. Interpreting Epidemiologic Evidence: Strategies for Study Design and Analysis. New York: Oxford University Press;

52. Weaver DR, Newman LS, Lezotte DC, Morley PS. Perceptions regarding workplace hazards at a veterinary teaching hospital. J Am Vet Med Assoc. 2010; 237:93-100. [PubMed: 20590501] 
Table 1

Demographic and lifestyle factors ${ }^{a}$ by pregnancy outcome.

\begin{tabular}{|c|c|c|c|c|}
\hline \multirow{2}{*}{$\begin{array}{l}\text { Study Subject Characteristics } \\
\text { Maternal pre-pregnancy BMI }\end{array}$} & \multicolumn{2}{|c|}{$\begin{array}{l}\text { Spontaneous Abortion <20 weeks gestation } \\
n=775(10.4 \%)\end{array}$} & \multicolumn{2}{|c|}{$\begin{array}{c}\text { Live Birth } \\
\mathrm{n}=6707(89.6 \%)\end{array}$} \\
\hline & \multicolumn{2}{|l|}{$25.3,16.1-50.0(5.7)$} & \multicolumn{2}{|c|}{$24.3,15.0-50.0(4.9)$} \\
\hline \multicolumn{5}{|l|}{ Mean, range, $(\mathrm{SD})$} \\
\hline Maternal Age & \multicolumn{2}{|l|}{$39.5,30-51(3.8)$} & \multicolumn{2}{|c|}{$36.4,29-50(3.4)$} \\
\hline \multicolumn{5}{|l|}{ Mean, range, (SD) } \\
\hline & $n$ & $\%$ & $n$ & $\%$ \\
\hline \multicolumn{5}{|l|}{ Maternal age category } \\
\hline$<=30$ & 6 & 0.8 & 175 & 2.6 \\
\hline $31-35$ & 112 & 14.5 & 2,609 & 38.9 \\
\hline 36-40 (referent) & 344 & 44.4 & 3,113 & 46.4 \\
\hline $41+$ & 313 & 40.4 & 810 & 12.1 \\
\hline \multicolumn{5}{|l|}{ Race } \\
\hline African American ${ }^{c}$ & 5 & 0.4 & 42 & 0.7 \\
\hline Asian & 12 & 1.1 & 119 & 1.9 \\
\hline Caucasian & 719 & 92.5 & 6,229 & 92.8 \\
\hline Hispanic & 11 & 1.3 & 101 & 1.5 \\
\hline Other & 15 & 2.2 & 100 & 1.5 \\
\hline Missing & 13 & 2.5 & 116 & 1.7 \\
\hline Parous & 535 & 68.2 & 5,698 & 84.6 \\
\hline Previous spontaneous abortion & 394 & 44.9 & 2,296 & 34.9 \\
\hline
\end{tabular}

First Trimester Lifestyle Factors

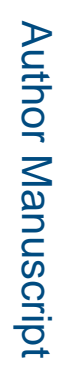

Caffeinated coffee servings $d$

None (reference)
$<=1$ cup per day
$>=2$ cups per day
Missing
Caffeinated soda/tea servings $d$
None (reference)
$<=1$ serving per day
$>=2$ servings per day
Missing

$\begin{array}{rrrr}412 & 55.1 & 4,151 & 61.6 \\ 232 & 28.8 & 1,874 & 28.1 \\ 130 & 15.8 & 676 & 10.2 \\ 1 & 0.4 & 6 & 0.1\end{array}$

Alcoholic beverage servings $d$

None (reference)

$<1$ drink per week

$>=1$ drink per week

Missing

$\begin{array}{rrrr}379 & 45.7 & 3,191 & 47.9 \\ 284 & 38.4 & 2,781 & 41.2 \\ 112 & 15.9 & 720 & 10.7 \\ 0 & 0.0 & 15 & 0.2\end{array}$

Smoked cigarettes per day

None (reference)

$\begin{array}{rrrr}584 & 76.8 & 5,459 & 81.2 \\ 120 & 14.8 & 926 & 13.9 \\ 70 & 8.3 & 315 & 4.8 \\ 1 & 0.1 & 7 & 0.1 \\ 710 & & & \\ & 92.2 & 6,316 & 94.2\end{array}$




\begin{tabular}{lccrr}
\hline Study Subject Characteristics & $\begin{array}{c}\text { Spontaneous Abortion <20 weeks gestation } \\
\mathbf{n = 7 7 5}(\mathbf{1 0 . 4 \% )}\end{array}$ & \multicolumn{2}{c}{$\begin{array}{c}\text { Live Birth } \\
\mathbf{n = 6 7 0 7}(\mathbf{8 9 . 6 \%})\end{array}$} \\
\hline$>=1$ cigarette per day & 65 & 7.6 & 389 & 5.8 \\
Missing & 0 & 0.0 & 2 & 0.0 \\
\hline
\end{tabular}

${ }^{a}$ Percentages for all variables except maternal age are directly standardized by year of age at current pregnancy

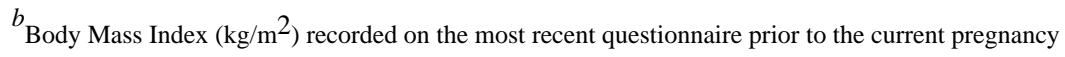

$c_{101}$ participants were missing data on race.

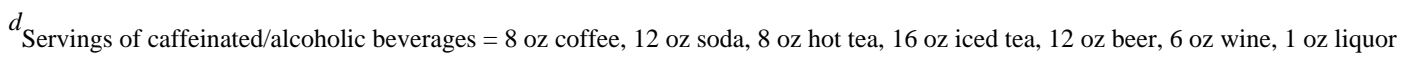




\section{Table 2}

Occupational factors ${ }^{a}$ by pregnancy outcome.

\begin{tabular}{|c|c|c|c|c|}
\hline & \multicolumn{2}{|c|}{$\begin{array}{r}\text { Spontaneous Abortion }<20 \text { weeks gestation } \\
n=775(10.4 \%)\end{array}$} & \multicolumn{2}{|c|}{$\begin{array}{r}\text { Live Birth } \\
\mathrm{n}=6707(89.6 \%)\end{array}$} \\
\hline \multicolumn{5}{|c|}{ Self-reported Occupational Exposures ${ }^{b}$} \\
\hline \multicolumn{5}{|c|}{ "On average, how many hours per day did you work with the following agents:" } \\
\hline \multicolumn{5}{|c|}{ "Anesthetic gases (e.g. nitrous oxide, halothane, enflurane, isoflurane)?" } \\
\hline$<1$ (reference) & 706 & 90.6 & 6,133 & 91.5 \\
\hline $1-4$ & 30 & 3.9 & 234 & 3.5 \\
\hline $4-8$ & 29 & 4.3 & 274 & 4.1 \\
\hline $9+$ & 10 & 1.2 & 66 & 1.0 \\
\hline \multicolumn{5}{|c|}{ "Anti-cancer drugs (e.g., Cytoxan, Fluroplex, Adrucil, Etoposide, 5-FU)?" } \\
\hline$<1$ (reference) & 727 & 92.8 & 6,453 & 96.2 \\
\hline $1-4$ & 39 & 5.8 & 202 & 3.0 \\
\hline $4-8$ & 8 & 1.3 & 45 & 0.7 \\
\hline $9+$ & 1 & 0.1 & 7 & 0.1 \\
\hline \multicolumn{5}{|c|}{ "Anti-viral drugs (e.g., Gancyclovir) or the interferons?" } \\
\hline$<1$ (reference) & 724 & 93.1 & 6,333 & 94.5 \\
\hline $1-4$ & 45 & 6.2 & 354 & 5.2 \\
\hline $4-8$ & 6 & 0.8 & 16 & 0.2 \\
\hline $9+$ & 0 & 0.0 & 4 & 0.1 \\
\hline \multicolumn{5}{|c|}{ "Sterilizing agents (e.g., ethylene oxide, formaldehyde, glutaraldehyde?" } \\
\hline$<1$ (reference) & 699 & 90.7 & 6,210 & 92.7 \\
\hline $1-4$ & 68 & 8.5 & 435 & 6.4 \\
\hline $4-8$ & 8 & 0.7 & 51 & 0.7 \\
\hline $9+$ & 0 & 0.0 & 11 & 0.2 \\
\hline \multicolumn{5}{|l|}{ "X-ray radiation?" } \\
\hline$<1$ (reference) & 650 & 81.5 & 5,781 & 86.3 \\
\hline $1-4$ & 116 & 17.1 & 852 & 12.6 \\
\hline $4-8$ & 8 & 1.2 & 61 & 0.9 \\
\hline $9+$ & 1 & 0.2 & 13 & 0.2 \\
\hline
\end{tabular}

\section{Work Schedule $^{b}$}

"What schedule did you usually work? If most of work hours are between 8 am-4pm, then it is "day"; if $4 \mathrm{pm}-$ midnight, then it is

"evening"; if midnight-8am, then it is "night."

Shift

$\begin{array}{lrrrr}\text { Days only (reference) } & 536 & 66.7 & 4,573 & 68.6 \\ \text { Nights only } & 89 & 12.7 & 575 & 8.5 \\ \text { Rotating shifts including nights } & 54 & 7.4 & 433 & 6.4 \\ \text { Day/Evening rotating; no nights } & 96 & 13.2 & 1,126 & 16.5 \\ \text { Hours worked (hours/week) } & & & & \\ 1-20 & 158 & 24.7 & 1,707 & 25.2 \\ 21-40 & 397 & 49.0 & 3,846 & 57.4\end{array}$




\begin{tabular}{|c|c|c|c|c|}
\hline \multirow[b]{2}{*}{$41+$} & \multicolumn{2}{|c|}{$\begin{array}{r}\text { Spontaneous Abortion }<20 \begin{array}{r}\text { weeks gestation } \\
n=775(10.4 \%)\end{array} \\
\end{array}$} & \multicolumn{2}{|c|}{$\begin{array}{r}\text { Live Birth } \\
\mathrm{n}=6707(89.6 \%)\end{array}$} \\
\hline & 220 & 26.2 & 1,154 & 17.4 \\
\hline
\end{tabular}

${ }^{a}$ Percentages for all variables except maternal age are directly standardized by year of age at current pregnancy

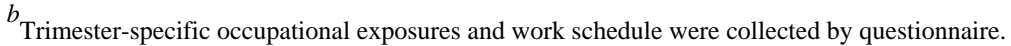


Table 3

Association between occupational exposures during the first trimester and spontaneous abortion

\begin{tabular}{|c|c|c|c|}
\hline \multirow[t]{2}{*}{ Occupational Exposures } & \multicolumn{3}{|c|}{ Odds Ratio (95\% Confidence Interval) } \\
\hline & Age-adjusted Models $a$ & Combined Exposures $b$ & Full Model ${ }^{c}$ \\
\hline \multicolumn{4}{|l|}{ Anesthetic gases } \\
\hline$<1$ hour per day (reference) & 1.0 & 1.0 & 1.0 \\
\hline $1+$ hours per day & $1.07(0.81-1.40)$ & $0.85(0.63-1.17)$ & $0.88(0.65-1.21)$ \\
\hline \multicolumn{4}{|l|}{ Antineoplastic agents } \\
\hline$<1$ hours per day (reference) & 1.0 & 1.0 & 1.0 \\
\hline $1+$ hours per day & $1.97(1.41-2.76)$ & $2.03(1.39-2.97)$ & $1.94(1.32-2.86)$ \\
\hline \multicolumn{4}{|l|}{ Antiviral agents } \\
\hline$<1$ hours per day (reference) & 1.0 & 1.0 & 1.0 \\
\hline $1+$ hours per day & $1.28(0.93-1.76)$ & $0.93(0.65-1.34)$ & $0.92(0.64-1.32)$ \\
\hline \multicolumn{4}{|l|}{ Sterilizing agents } \\
\hline$<1$ hour per day (reference) & 1.0 & 1.0 & 1.0 \\
\hline $1+$ hours per day & $1.46(1.12-1.91)$ & $1.46(1.09-1.95)$ & $1.39(1.03-1.87)$ \\
\hline \multicolumn{4}{|l|}{ X-ray radiation } \\
\hline$<1$ hour per day (reference) & 1.0 & 1.0 & 1.0 \\
\hline $1+$ hours per day & $1.31(1.05-1.62)$ & $1.27(1.01-1.60)$ & $1.22(0.97-1.55)$ \\
\hline
\end{tabular}

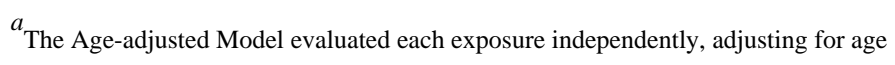

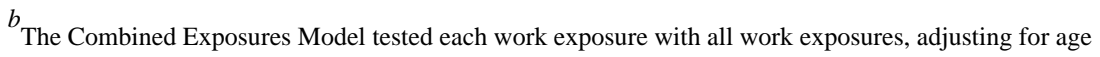

${ }^{c}$ The Full Model includes all work exposures, adjusting for age, parity, shift work, and hours worked. 


\section{Table 4}

Association between occupational exposures during the first trimester and early versus late spontaneous abortion

\begin{tabular}{|c|c|c|c|}
\hline \multirow[t]{2}{*}{ Occupational Exposures } & \multicolumn{3}{|c|}{ Odds Ratio (95\% Confidence Interval) } \\
\hline & $\begin{array}{l}\text { Early Spontaneous Abortion }(<12 \\
\text { weeks) } \\
n=575\end{array}$ & $\begin{array}{l}\text { Late Spontaneous Abortion (12-20 } \\
\text { weeks) } a, b \\
\mathrm{n}=\mathbf{2 0 0}\end{array}$ & $\begin{array}{l}\text { Difference of effect } \\
\text { estimates between early } \\
\text { and late } c \\
\text { P-value }\end{array}$ \\
\hline \multicolumn{4}{|l|}{ Anesthetic gases } \\
\hline$<1$ hour per day (reference) & 1.0 & 1.0 & \\
\hline $1+$ hours per day & $0.94(0.66-1.33)$ & $0.79(0.44-1.42)$ & 0.6 \\
\hline \multicolumn{4}{|l|}{ Antineoplastic agents } \\
\hline$<1$ hours per day (reference) & 1.0 & 1.0 & \\
\hline $1+$ hours per day & $2.13(1.39-3.27)$ & $1.39(0.68-2.84)$ & 0.3 \\
\hline \multicolumn{4}{|l|}{ Antiviral agents } \\
\hline$<1$ hours per day (reference) & 1.0 & 1.0 & \\
\hline $1+$ hours per day & $0.76(0.50-1.18)$ & $1.35(0.75-2.44)$ & 0.1 \\
\hline \multicolumn{4}{|l|}{ Sterilizing agents } \\
\hline$<1$ hour per day (reference) & 1.0 & 1.0 & \\
\hline $1+$ hours per day & $1.13(0.80-1.60)$ & $2.10(1.29-3.41)$ & 0.04 \\
\hline \multicolumn{4}{|l|}{$\mathrm{X}$-ray radiation } \\
\hline$<1$ hour per day (reference) & 1.0 & 1.0 & \\
\hline $1+$ hours per day & $1.31(1.01-1.71)$ & $0.98(0.63-1.53)$ & 0.3 \\
\hline
\end{tabular}

${ }^{a}$ Adjusted for all work exposures, age, parity, shift work categories, and hours worked per week.

${ }^{b}$ Excludes the 575 pregnancies ending in early spontaneous abortion

${ }^{c}$ To assess statistically significant differences between early and late spontaneous abortion models, we calculated p-values for common effects with a chi-square test statistic using the maximum likelihood estimates from the logistic regressions. 